\title{
Disclosure tone and shareholder litigation
}

\author{
Jonathan L. Rogers, Andrew Van Buskirk ${ }^{1}$, and Sarah L. C. Zechman \\ University of Chicago \\ Booth School of Business \\ 5807 South Woodlawn Avenue \\ Chicago, IL 60637
}

July 2009

\begin{abstract}
We examine the relation between disclosure tone and shareholder litigation for a sample of firms involved in class action securities litigation. Specifically, we use text analysis software to investigate whether sued firms' earnings announcements are systematically more optimistic in tone than a sample of non-sued firms in similar economic circumstances and industries. We find that disclosures issued by sued firms during the class action damage period are significantly more optimistic than those of non-sued firms. We also provide evidence that plaintiffs explicitly target the more optimistic disclosure language within earnings announcements when initiating shareholder lawsuits. Finally, we find that managers of sued firms issue more forecasts than their non-sued counterparts. In total, our results are consistent with the use of optimistic language and the issuance of management forecasts increasing firms' likelihood of being sued.
\end{abstract}

Keywords: Securities litigation, disclosure, tone, earnings announcements JEL Classifications: G38, K22, M41, M48

\footnotetext{
${ }^{1}$ Corresponding author: Phone: (773) 834-1712 Email: avanbusk@ chicagogsb.edu

We had helpful discussions with John Core and Doug Skinner and benefitted from comments of workshop participants at the Universities of Arizona and Chicago and conference participants at the Tilburg University Accountancy Spring Camp. We thank Woodruff-Sawyer for providing litigation data, Craig Carroll for assistance with Diction software, and Burch Kealey for assistance with the directEDGAR program. We gratefully acknowledge the financial support of the University of Chicago Booth School of Business.
} 


\section{Introduction}

Managers face a fundamental tradeoff in financial reporting - they have incentives (e.g., career concerns or compensation) to present information in a favorable manner, but face penalties when they misrepresent their firm's economic condition. The forces that constrain the manipulation of managers' quantitative disclosures are well-known and extensively researched. For example, investors can discount statements from managers who had previously issued inaccurate forecasts, auditors provide assurance that the firm has prepared the financial statements in accordance with GAAP, the SEC ensures that firms provide details of the estimates and assumptions used to prepare those statements, and shareholders can initiate private securities lawsuits if they believe that managers' misrepresentations led to inflated stock prices.

Managers also convey information in more qualitative or subtle ways. These "soft" communications are likewise subject to managerial embellishment, but are less verifiable than quantitative results. For example, managers tend to blame external factors for poor outcomes and take credit for good outcomes (Bettman and Weitz 1983; Baginski et al. 2000). In spite of the potential for manipulation, soft information influences investors' evaluation of the firm: optimistic (pessimistic) tone in news releases is associated with positive (negative) stock price responses (Davis et al. 2008; Henry 2008; Tetlock et al. 2008). Given the difficulty of auditing and verifying soft information, we expect shareholder litigation to play an important role in monitoring such information.

Several studies have investigated the relation between discretionary disclosure and litigation (e.g., Skinner 1994, 1997; Francis et al. 1994; Johnson et al. 2001; Baginski et al. 2002; Field et al. 2005), focusing primarily on the link between management earnings forecasts and litigation. In particular, these studies examine the link between forecasting bad news and 
subsequent litigation. On one hand, this focus is not surprising - machine-readable forecast data is widely available, and managers and regulators have long shown significant interest in how forecasts are associated with litigation. ${ }^{1}$ On the other hand, existing research tells us little about how other aspects of discretionary disclosure may relate to litigation risk.

In this paper, we examine the relation between disclosure tone and shareholder litigation. Our goal is to determine whether managers' use of soft information in the form of optimistic language contributes to the likelihood of being sued by shareholders. Our interest in disclosure tone, specifically optimism, seems natural in the context of securities litigation. Although the particular allegations vary from lawsuit to lawsuit, they share a common underlying theme: Investors allege that their prior expectations regarding firm value were too high, and those overly optimistic expectations were based on the firm's disclosures. A link between disclosure tone and litigation risk would indicate that managers have the ability to influence the probability of being sued by changing their disclosure tone. Such a link would also be consistent with shareholder litigation having merit, even when that litigation is based on difficult-to-verify allegations. ${ }^{2}$

The link between disclosure and litigation is not only of interest to investors, who rely on representationally faithful disclosure to allocate capital, and managers, who want to limit their exposure to litigation, but also to regulators. Regulators in the U.S. have expressed concern that shareholder litigation poses an undue burden on firms and contributes to the weakening position of the U.S. financial markets. ${ }^{3}$ The costs of litigation are more clearly identifiable than the

\footnotetext{
${ }^{1}$ See, for example, the Private Securities Litigation Reform Act of 1995, which provide greater legal protection for the issuance of forward-looking statements.

${ }^{2}$ Of course, an observed relation between disclosure tone and litigation would not be sufficient evidence to show that lawsuits have merits. We are unable to speak to whether managers actually believed what they disclosed or, alternatively, purposefully issued misleading statements (the requirement for successful action under Rule 10b-5). A relation between disclosure choices and litigation is simply a necessary condition for lawsuits having merit.

${ }^{3}$ For example, a report commissioned by Senator Charles Schumer and New York City Mayor Michael Bloomberg reveals that survey participants view the U.S. legal system as less predictable and less fair than that of the U.K.
} 
benefits. Obvious costs include the opportunity costs associated with firms diverting resources from producing goods and services to defending executives, the payment of substantial insurance premiums to protect officers and directors ${ }^{4}$, and the consumption of significant judicial resources $^{5}$. Critics of the current litigation environment argue that these costs are unwarrantedlawsuits may be frivolous and aimed at extracting large settlements from firms, regardless of the firm's guilt. ${ }^{6}$

The current litigation environment is predicated on the belief that the costs are more than offset by the benefits. Potential benefits include compensation for injured parties and the deterrence of fraud. As Coffee (2006) notes, securities class actions are unlikely to serve an effective compensatory role for injured shareholders - damages are simply transferred from one set of shareholders to another (overlapping) set of shareholders, minus a significant cut for the attorneys - leaving fraud deterrence as the most likely potential benefit. A necessary condition for litigation to be an effective deterrent is that lawsuits must be (at least to some extent) avoidable. That is, if managers perceive that their behavior does not influence the likelihood of being sued, they will have no incentive to alter their behavior. Our study provides insights as to whether managers' disclosure choices do, in fact, influence their exposure to litigation.

We begin our analysis by investigating which particular categories of disclosures are most likely to affect the probability of litigation. This investigation involves two tests: one

\footnotetext{
${ }^{4}$ Directors \& Officers (D\&O) Insurance costs for Fortune 500 firms are more than six times higher in the U.S. than in Europe (Interim Report of the Committee on Capital Markets Regulation 2006, pg. 78).

${ }^{5}$ Securities litigation accounted for approximately 47\% of all federal class actions in 2002, 2003, and 2004, dwarfing other class action categories such as Contract, Tort Actions, Civil Rights, Antitrust, and Labor (Coffee 2006).

${ }^{6}$ In Stoneridge Investment Partners, LLC v. Scientific-Atlanta, Inc. (October 2007), the US Supreme Court noted that "extensive discovery and the potential for uncertainty and disruption in a lawsuit could allow plaintiffs with weak claims to extort settlements from innocent companies"
} 
based on the specific statements cited as misleading in the plaintiffs' complaints ${ }^{7}$ and one based on the timing of the beginning of the class period. We review a randomly-selected subsample of the complaints and find that earnings announcements are the most consistently cited type of communication. For the full sample, we then examine how frequently the first date of alleged misconduct (i.e., the beginning of the damage period) fell on an earnings announcement date. The majority of damage period start dates coincide with an earnings release, again suggesting that earnings announcements are an important (and perhaps the most important) disclosure affecting litigation risk.

We then return to the subsample and extract the quoted statements from each earnings announcement cited in the complaint. Using text-analysis software to measure optimism, we compare the tone of the quoted language to the tone of the remainder of the earnings announcement (i.e., the non-quoted portion of the cited earnings announcement). We find that the particular statements plaintiffs choose to quote in their class action complaints are significantly more optimistic in tone than the remainder of the document. Although this result is not surprising, it bolsters the view that plaintiffs target optimistic language in their lawsuits. Furthermore, the result provides assurance that our software is capturing the types of optimistic statements targeted by plaintiffs.

While the above result is consistent with more optimistic language exposing the firm to greater litigation risk, we view this evidence as relatively weak. After all, virtually all firms are likely to make some optimistic statements (even if the aggregate tone of their disclosures is quite negative). To learn whether sued firms' disclosures, taken as a whole, are unusually optimistic, our main analysis compares the tone of the sued firms' earnings announcements to the tone of

${ }^{7}$ In their complaints, plaintiffs are required to cite the specific statements alleged to be misleading, and the reasons the statements were misleading. 
disclosures made by other firms in the same industry and experiencing similar economic circumstances (e.g., similar size, performance, and time period).

Both univariate and multivariate tests reveal that sued firms use substantially more optimistic language in their earnings announcements than do non-sued firms. Specifically, a one standard deviation change in net optimism (optimistic tone less pessimistic tone) is associated with a $52 \%$ increase in the likelihood of being sued. Collectively, our results indicate a strong link between disclosure tone and litigation. The difference in tone between sued and non-sued firms' disclosures is in accord with plaintiff allegations that managers issued overly optimistic disclosures during the damage period. This difference, combined with our evidence that plaintiffs cite statements with greater optimism as false or misleading, suggests that managers can reduce their risk of facing litigation by dampening the tone of their disclosures.

In additional analysis, we show that both optimistic and pessimistic tones are individually associated with the likelihood of being sued. (More optimistic language suggests increased litigation risk, while more pessimistic language suggests decreased litigation risk.) In other words, our net optimism result is not driven solely by optimistic terms, but rather the combined effect of optimistic and pessimistic terms. An implication is that firms can reduce their litigation risk either by decreasing the use of optimistic language or by increasing the use of more cautionary, pessimistic language to offset the existing level of optimistic terms.

Our study differs from prior research on whether changes in disclosure behavior can influence litigation risk (Skinner 1994, 1997; Field et al. 2005). These papers ask whether preempting bad earnings news can reduce the likelihood of being sued. In contrast, rather than focusing on disclosures that reveal impending earnings disappointments, we are interested in the disclosures that are claimed to be misleading and allegedly led to overoptimistic expectations. 
Our study is most closely related to analysis performed by Francis et al. (1994), who look at the disclosures in the year prior to adverse earnings news for both sued and non-sued firms in an effort to identify differential optimism across the two groups. They find no significant difference between the two groups of firms, but, as we discuss in Sections 3 and 4, our empirical methodology allows for more powerful tests than those used by Francis et al.

Additionally, our forecast result builds on the findings of Rogers and Van Buskirk (2008), who show that managers reduce the number of forecasts issued (as well as other disclosures) after being sued, relative to matched firms that were not sued. Our finding, that forecast issuance is positively associated with the probability of a lawsuit, suggests that the observed decrease in forecasts after a lawsuit arises from the sued managers accurately updating their understanding of what types of disclosures put the firm at risk, and altering their disclosures accordingly.

The remainder of this paper is organized as follows. Section 2 discusses related research. Section 3 details our research design, while Section 4 describes our sample data. Sections 5 and 6 report the empirical results. Section 7 concludes.

\section{Prior Research}

\subsection{Disclosure tone}

Studies have shown that managers frequently use discretion to describe their firms' results in a self-serving fashion. Bettman and Weitz (1983) evaluate the Letters to Shareholders presented in annual reports, finding that unfavorable outcomes are generally blamed on external (and uncontrollable) factors relative to factors attributed to more favorable outcomes. Baginski et al. (2000) draw a similar conclusion from an examination of management forecasts. Managers 
also use discretion to frame results in a positive light. Lougee and Marquardt (2004) give evidence that managers strategically disclose pro forma earnings when they miss earnings benchmarks. Schrand and Walther (2000) show that managers strategically select a prior-period earnings benchmark (e.g., by excluding a prior period gain) to avoid the appearance of negative earnings surprises. McVay (2006) describes how managers appear to opportunistically shift expenses from core expenses to special items in an effort to inflate "core" earnings.

Prior research has also demonstrated that managers selectively disclose good news, and are less forthcoming with bad news. Lang and Lundholm (2000) study disclosure behavior before seasoned equity offerings and conclude that managers "hype" their stock by increasing discretionary disclosure, particularly optimistic disclosures. Rogers and Stocken (2005) show that managers are more likely to bias their earnings forecasts in situations where the market has greater difficulty detecting misrepresentation. Kothari et al. (2008b) hypothesize and find that managers delay the disclosure of bad news relative to good news. Li (2008) finds support for the hypothesis that managers obfuscate poor results by issuing less readable disclosures.

Evidence reveals that these discretionary disclosure choices affect the perception of investors and analysts. For example, the increase in optimistic disclosures identified by Lang and Lundholm (2000) was associated with increased stock prices leading up to the equity offerings. Similarly, the level of optimism in an earnings announcement is positively associated with the market's short-term response to the announcement (Henry 2008; Demers and Vega 2008; Davis et al. 2008). The same relation holds for information generated outside the firm Tetlock et al. (2008) find that returns are correlated with the tone of firm-specific news stories even after controlling for earnings news and analyst forecasts. 


\subsection{Shareholder litigation}

An important mechanism limiting managers' opportunistic disclosures is shareholder litigation, generally taking place under Rule $10 \mathrm{~b}-5$ of the Securities Exchange Act of $1934 .^{8}$ Rule 10b-5 makes it unlawful to "make any untrue statement of a material fact or to omit to state a material fact necessary in order to make the statements made... not misleading". ${ }^{9}$ Under this rule, investors can initiate legal action after being harmed by a defendant's misrepresentations. These actions typically consist of complaints against the firm and its managers for providing misleading information about the firm, resulting in shareholder losses. Complaints may technically arise from either purchasers (alleging share prices were too high when they purchased) or sellers (alleging share prices were too low when they sold). The vast majority of cases, however, involve purchasers alleging that the firm's misrepresentations led to stock prices that were too high, and subsequent stock price declines (Francis et al. 1994). ${ }^{10}$

The claimed link between optimistic disclosure and litigation is often stated explicitly in class action complaints. For example, the plaintiffs in In Re VoiceFlash Networks, Inc. Securities Litigation (Second Amended Complaint, May 31, 2005) alleged that "the news that VoiceFlash would liquidate came on the heels of numerous highly optimistic announcements by the defendants touting the success of the Company's business condition and financial performance." As another example, a complaint against Metris Companies (2002, U.S. District Court, District of Minnesota) includes the allegation that the CEO "offered a hopelessly positive spin on his Company's capital plan”.

\footnotetext{
${ }^{8} 15$ U.S.C. 78 a et seq

${ }^{9} 17$ CFR $\$ 240.10 b-5$

${ }^{10}$ One recent counterexample is that of Tyco (Stevenson v. Tyco International, filed April 29, 2005) which was sued by sellers of stock for allegedly providing overly pessimistic statements during the damage period.
} 
Although shareholder lawsuits frequently claim that optimistic statements made by managers caused the damages suffered by plaintiffs, there is little evidence regarding the strength of these claims. In fact, this question relates to a broader literature questioning the merits of shareholder litigation altogether. Alexander (1991) casts doubt on the idea that merits "matter". She reports that, for a sample of computer-industry lawsuits in 1983, settlement amounts are a relatively constant percent of estimated damages across all sample suits, instead of the variation expected if individual cases have differing degrees of merit. Similar doubts led to the enactment of the Private Securities Litigation Reform Act (PSLRA) in 1995, which instituted numerous changes in the securities class action process in an effort to curb frivolous lawsuits. ${ }^{11}$ Even after the passage of the PSLRA, though, there is still concern that lawsuits are initiated and settled without regard to the underlying merits of the case. ${ }^{12}$

\subsection{Relation between disclosure and shareholder litigation}

Much of the existing literature on the link between disclosure and litigation is concerned with a firm's ability to avert litigation via timely disclosure of bad news. Skinner (1994) notes that firms tend to preempt bad earnings news more frequently than good earnings news, and conjectures that they do so in order to avoid litigation. Francis et al. (1994) sample a group of firms in high-litigation risk industries and point out that sued firms tend to issue forecasts more frequently than firms that are not sued, casting doubt on the notion that prompt disclosure deters litigation. Skinner (1997) examines a broader sample of firm-quarters that led to shareholder litigation and finds results consistent with Francis et al. (1994), but argues that forecast issuance

\footnotetext{
${ }^{11}$ Johnson et al. (2007) examine a sample of high-technology firms and find a shift away from forecast-related litigation, which is consistent with the increased protection of forward-looking statements provided by the PSLRA.

${ }^{12}$ In a recent example, Baker and Griffith (2008) conclude that the settlement of securities class actions often depends on non-merit related factors such as the firm's insurance policy structure and limits.
} 
may limit the costs of litigation even if it does not prevent a suit. He finds some evidence that early disclosure can reduce expected litigation costs by reducing settlement amounts, but notes this relation is endogenous as both the incentive to disclose early and the expected settlement amount are increasing in the damages suffered by shareholders. Field et al. (2005) explicitly model the endogeneity and conclude that disclosure potentially deters litigation.

The prior studies generally concentrate on firms about to experience negative earnings news, and then examine whether timely disclosure of the negative news deters litigation. They do not investigate the allegedly misleading disclosures made in the damage period, or how those disclosures compare to disclosures issued by non-sued firms. The exception is Francis et al. (1994), who focus on the disclosures that reveal adverse earnings news and also study disclosures in the year prior to the adverse earnings news for both sued and non-sued firms. They read disclosures and manually code them as being optimistic, pessimistic, or neutral and find no statistically significant difference in the proportions of optimistic/pessimistic/neutral disclosures between sued and non-sued firms. While the Francis et al. (1994) analysis is in the spirit of our study, we explain in the next section how our empirical design allows for more powerful tests of the relation between tone and litigation.

\section{Empirical Design}

We analyze the tone of disclosures issued by firms sued for violating Rule 10b-5. Our analysis focuses on those disclosures made during the class action period (i.e., the period in which a company is alleged to have been engaged in improper conduct), which means that we analyze more of a firm's disclosures when the damage period is long and fewer disclosures when the damage period is short. This contrasts with Francis et al. (1994), whose analysis is based on 
disclosures in the year prior to an adverse earnings event, regardless of whether those disclosures occurred in the damage period.

As our interest is in purely disclosure-related litigation, we eliminate lawsuits where allegations related to IPO allocations, earnings restatements, mergers and acquisitions, or options backdating. We also restrict our analysis to lawsuits for which all of the alleged misstatements occurred after the enactment of Regulation FD (Fair Disclosure). This restriction ensures that the disclosures in question were all in the public sphere (and available for us to examine). ${ }^{13}$

\subsection{Content analysis}

As noted earlier, Francis et al. (1994) categorize disclosures as either optimistic, pessimistic, or neutral based on a subjective reading of the document. We use Diction 6.0, a dictionary-based text analysis program, to quantify optimistic tone on a continuous scale. This software parses electronic documents and registers the occurrence of pre-defined terms within those documents.

Our variable of interest, Net Optimism, is defined by Diction as "language endorsing some person, group, concept, or event or highlighting their positive entailments". The variable is calculated as the sum of three positive components (praise, satisfaction, and inspiration) minus the sum of three negative components (blame, hardship, and denial). We then scale the calculated value by the non-numeric word count of the document and multiply by 100 to obtain an optimism percent for each document. Net Optimism can be interpreted as the \% of the document's non-numerical words that are identified by Diction as optimistic, minus the \% of the

\footnotetext{
${ }^{13}$ For example, pre-Reg FD claims may rely on reports of private communications between analysts and the firm. In those situations, we cannot characterize the type of information communicated, or the tone with which it was communicated.
} 
document's non-numerical words that are identified as pessimistic. Positive scores reflect net optimism while negative scores reflect net pessimism. To illustrate the types of words identified as increasing or decreasing optimism, Appendix A lists a subset of the terms in each of the 6 component dictionaries.

This method of quantifying disclosure language has become increasingly popular in recent years ${ }^{14}$, and has several advantages over a subjective categorization. First, Diction software has been used to measure tone in many contexts, including presidential speeches (Bligh et al. 2004); television vs. newspaper coverage of major events (Cho et al. 2003); corporate annual reports (Yuthas et al. 2002); and other business communications (Ober et al. 1999; Henry 2008), which provides comfort that Diction's quantitative measures capture semantic distinctions similar to those that motivate our study. Second, the measure of optimism is continuous rather than categorical, such as the measure used by Francis et al. (1994), which increases the power of our analysis. Third, the measure is normalized by word count, which allows for comparisons between disclosures of vastly different lengths (a factor that is especially important when comparing entire documents to brief excerpts from those documents). Finally, the process is objective, can be applied to large quantities of text, and provides results that are replicable by other researchers.

\subsection{Control sample}

Our initial textual analysis is a comparison between the tone of specific statements quoted in lawsuits and the tone of the remainder of the document from which those statements

\footnotetext{
${ }^{14}$ Recent working papers using Diction software to analyze narrative content include Davis et al. (2008) and Demers and Vega (2008). Studies using similar methods include Kothari et al. (2008a), who analyze a variety of print disclosures, including the MD\&A section of 10-Ks, and Mayew and Venkatachalam (2008), who analyze recorded audio from conference calls.
} 
were extracted. This comparison, aimed at understanding whether plaintiffs appear to target optimistic language in their lawsuits, uses the firm as its own benchmark. In contrast, our principal analysis focuses on the overall optimism in the sued firms' disclosures, regardless of whether those disclosures were cited in the complaint. This analysis requires some base level of optimism to use as a benchmark in evaluating the optimism of the sued firms' disclosures. We select a control group of non-sued firms and use their measured optimism as that benchmark. As discussed below, our matching procedure enables us to compare disclosures issued by firms experiencing comparable economic performance.

Firms are typically sued after a period of poor performance (Rogers and Van Buskirk 2008). ${ }^{15}$ Because discretionary disclosure is correlated with economic performance (Miller 2002), it is reasonable to expect that disclosure tone would also vary with performance. As such, a comparison of sued firms' disclosures to disclosures made by random firms would likely be biased in favor of finding differences across the two groups. As a more appropriate benchmark, we select a matched sample of firms sharing similar size, industry, and stock price performance over a comparable time period.

Our specific matching procedure is as follows: For each sued firm, we use $\mathrm{I} / \mathrm{B} / \mathrm{E} / \mathrm{S}$ data to identify the last earnings announcement prior to the beginning of the damage period and the first earnings announcement after the end of the damage period, and measure the stock return during that window. ${ }^{16}$ Because the beginning and ending dates of the return measurement window are outside of the class action damage period, the stock prices can reasonably be

\footnotetext{
${ }^{15}$ This is, of course, a broad generalization. For example, Hansen Natural Corporation was sued on 11/29/2006 for alleged misstatements made between 11/12/2001 and 11/9/2006. During that period (including the effect of the revealing disclosure on 11/9/2006), Hansen's stock return was greater than 5,000\%.

${ }^{16}$ If the damage period begins on an earnings announcement date, the starting date for measuring returns is three trading days prior to that earnings announcement. Similarly, if the damage period ends on an earnings announcement date, the ending date is three trading days after the earnings announcement.
} 
assumed to reflect an unbiased measure of firm value. This implies that the return over that period is an unbiased measure of the firm's performance, even if the stock price within the damage period was (allegedly) inflated. From the population of all firms in the same 2-digit SIC code and the same size decile, we select the non-sued firm having the closest stock return measured over a period encompassing the same number of earnings announcements. ${ }^{17}$

This matching process is similar to that used by Rogers and Van Buskirk (2008), but differs in two ways. First, we require industry matching, based on the expectation that disclosure content is likely to be similar within industries (e.g., pharmaceutical firms discussing clinical trials) as well as the observation that litigation risk appears to be clustered in certain industries in a given time period (Securities Class Action Filings 2008: A Year In Review 2009). ${ }^{18}$ Second, our windows span from earnings announcement to earnings announcement, rather than a strict calendar matching based on the sued firm's damage period. The centrality of earnings announcement dates is based on the frequency with which earnings announcements are cited in the class actions complaints, as we discuss in detail in Section 5.1.

\title{
4. Sample Data
}

\author{
4.1. Litigation Data
}

\footnotetext{
${ }^{17}$ We require that the match firm's measurement window begins within 90 days of the beginning of the sued firm's measurement window, ensuring that the periods span similar calendar time. We further require the returns of the matched firm to be within $25 \%$ of the sued firm's returns to ensure a reasonable performance match.

${ }^{18}$ We note that the industries subject to litigation are not constant over time - a Cornerstone Research report shows that from 2000-2008, the most-frequently sued S\&P sector in a calendar year included Technology (2000 and 2006), Communications (2001), Utilities (2002), Consumer Non-Cyclical (2003 and 2005), and Financial (2004, 2007, and 2008). Only the Basic Materials, Consumer Cyclical, Energy, and Industrial sectors failed to reach the highest place in any year (Securities Class Action Filings 2008: A Year In Review 2009).
} 
We obtained litigation data from Woodruff-Sawyer, a San Francisco-based insurance brokerage firm. ${ }^{19}$ The criteria for inclusion in this dataset are:

- The suit was filed in federal court against a corporation.

- The suit alleged fraud involving the price of the defendant's common stock.

- The case included allegations of material misrepresentations and omissions regarding the true health and potential of the defendant company.

We are interested in disclosure-related lawsuits, so we eliminate litigation related to mergers \& acquisitions, IPOs, option backdating, and earnings restatements. Requiring CRSP, Compustat, First Call, and I/B/E/S information reduces the number of post-Reg FD lawsuits to 410. Our content analysis requires at least one earnings announcement within the damage window, and our matching procedure requires an earnings announcement immediately before (after) the beginning (end) of the damage period. A total of 346 lawsuits meet all of the requirements for our content analysis and matching procedures. The characteristics of these lawsuits are summarized in Table 1.

\subsection{Descriptive Statistics}

The lawsuits are varied both in firm type and in the duration of the damage period. The population of 346 lawsuits were filed from 2001-2008, with alleged periods of misconduct ranging from less than one month to five years (Table 1, Panels A and B). Just over 50\% of the lawsuits fall in 5 industries: Chemicals and Allied Products (SIC 28) with 17\%, Business

\footnotetext{
${ }^{19}$ Woodruff-Sawyer aggregates the data for its own uses, one of which is to advise its clients on D\&O insurance coverage. Woodruff-Sawyer uses many sources to generate this data, including Stanford's Securities Class Action Clearinghouse (SCAC), Securities Class Action Services, SEC filings, and wire services. For a further discussion, see Rogers and Van Buskirk (2008).
} 
Services (SIC 73) with 13\%, Electronics (SIC 36) with 8\%, Measurement, Analysis, and Control Instruments (SIC 38) with 7\%, and Insurance Carriers (SIC 63) with 6\% (Panel C).

\section{Empirical Analysis}

\subsection{Analysis of Class Action Complaints}

Our initial inquiry relates to the types of communications from which the alleged misstatements are drawn. From the 410 lawsuits with available data on CRSP, Compustat, First Call, and I/B/E/S, we review a random sample of 20 and categorize the cited disclosures. Like the full population of firms, the sample lawsuits were filed between 2001 and 2008, with damage periods ranging from less than one month up to five years (Table 2, Panels A and B).

Securities lawsuits typically contain the following elements:

- A specification of the period during which the alleged misstatements were made (i.e., the damage period), which also identifies the pool of potential class members (i.e., purchasers or sellers of the firm's stock during the damage period).

- A summary of the complaint in a narrative form.

- The jurisdiction and venue under which the claims are being made.

- The parties (i.e., plaintiffs and defendants) to the suit. Commonly, both the firm and the individual managers are named as defendants.

- The substantive allegations, including the specific statements alleged to be false or misleading. Additionally, plaintiffs must present arguments that managers knew they were providing misleading information or, in other words, acted with scienter.

- If plaintiffs cite forward-looking statements as misleading, arguments for why safe harbor protection does not apply.

- The mechanism by which the truth was revealed (e.g., the firm issues a press release revealing substantially worse news than previously expected). 
Our interest is in the alleged false and misleading statements. For each of the 20 randomly-selected lawsuits, we obtain the reference complaint from the Stanford Securities Class Action Website (http://securities.stanford.edu/). We review the substantive allegations of each lawsuit and categorize each alleged misstatement based on the type of communication in which that statement appeared. Table 2, Panel $\mathrm{C}$ gives a summary of this review.

The 20 complaints that we reviewed cite a total of 294 communications, comprising earnings announcements, conference calls (both earnings announcement-related and standalone), press releases, media interviews, investor conferences, and SEC filings. Earnings announcements were cited most consistently, appearing in 18 of the 20 lawsuits. The majority of lawsuits also cited non-earnings announcement press releases (75\%), 10-Qs (70\%), earningsrelated conference calls (60\%), and 10-Ks (55\%).

Of the 294 communications, 108 (37\%) were earnings-related, either the press release itself (80) or the associated conference call (28). SEC filings accounted for 75 (26\%) of the cited communications, most frequently $10-\mathrm{Qs}(51)$ and $10-\mathrm{Ks}(20)$. Of the remaining categories, nonearnings announcement press releases were by far the most frequent, accounting for 91 (31\%) of the cited statements.

As noted in Panel C, 91 of the documents cited were press releases that were not earnings announcements, while 80 were earnings announcements. However, only $75 \%$ of the lawsuits cite at least one non-earnings press release, while $90 \%$ cite at least one earnings announcement. Three sued firms cause the distribution of non-earnings press releases to be skewed: EVCI Career Colleges, Pozen Inc., and Xethanol Corporation account for 42\% (38/91) of the nonearnings press releases cited. Excluding these 3 lawsuits, earnings-related disclosures account 
for $41 \%$ of the cited statements, SEC filings account for $27 \%$ of the cited statements, and nonearnings press releases account for $23 \%$ of the cited statements.

We next examine the statements that plaintiffs quote in the complaint (i.e., the particular statements alleged to be misleading). Earnings announcements are frequently cited for commentary regarding current period results, as well as for managers' outlook on future results. Sometimes that outlook is quantitative, other times qualitative, as illustrated in the first two examples in Appendix B. When citing earnings-related conference calls, some lawsuits quote the lead-off, scripted discussion (like Appendix B, Example 3), while others quote managers' responses in the Q\&A portion of the call. As Appendix B illustrates, the text quoted (and emphasized) in earnings announcements frequently includes positive qualitative disclosures that would be categorized by Diction as optimistic.

SEC filings are frequently referenced in lawsuits for reasons other than managers' discretionary statements. Some complaints reference the filing only for the CEO/CFO certifications required by the Sarbanes-Oxley Act of 2002. Others cite SEC filings to reaffirm information that was already cited from a prior earnings announcement. Finally, some lawsuits simply point to "boilerplate" management representations. For example, a suit against Midway Games includes references to 6 different SEC filings, 3 of which simply quote the $10-\mathrm{Q}$ as stating:

The accompanying unaudited condensed consolidated financial statements have been prepared in accordance with generally accepted accounting principles for interim financial information, the instructions to Form 10-Q and Article 10 of Regulation $S-X \ldots$ In the opinion of management, all adjustments (consisting of normal recurring accruals) considered necessary for a fair presentation have been included. 
As noted in Table 2, Panel C, plaintiffs frequently reference non-earnings press releases. However, these press releases are often cited for information similar to that disclosed in earnings announcements, such as new joint ventures, implicit or explicit earnings guidance, updates on the status of clinical trials, or recurring announcements of non-GAAP performance measures. The latter is illustrated in Appendix B, Example 4. In this complaint against EVCI Career Colleges, plaintiffs repeatedly cite the firm's announcements of student enrollment as false or misleading.

Characteristics of the entire sample of 410 lawsuits substantiate the importance of earnings announcements in lawsuit filings. More than $96 \%$ have damage periods encompassing at least one earnings announcement date. Over half of the lawsuits' damage periods begin on an earnings announcement date, suggesting that the earnings announcement (or earnings-related conference call) contained the first allegedly misleading statement in that complaint.

Overall, these analyses indicate that earnings announcements are an important (perhaps the most important) source of alleged misrepresentations. Based on the consistency and prevalence with which earnings announcements are cited in class action complaints, along with the availability of earnings announcements for potential control firms, we focus on earnings announcement disclosures in the remainder of our analyses.

\subsection{Analysis of Quoted Language}

We next compare the characteristics of the excerpts to the characteristics of the remainder of the document to determine whether plaintiffs focus on the more optimistic language in the documents. This also provides confirmation that the Diction software is capturing the type of the qualitative language cited by plaintiffs in their complaints. Based on the quotes cited for our subsample of 20 lawsuits, we identify what types of statements investors and their attorneys 
target. Plaintiffs reveal the particular disclosures they view as misleading by not only referencing the disclosure, but presenting excerpts of that disclosure in the text of the lawsuits. ${ }^{20}$ Thus, instead of a formal hypothesis test, we view this initial analysis as jointly confirming the general nature of the plaintiff allegations and the efficacy of the Diction software for our purposes.

For each of the 20 lawsuits described in Section 5.1, we attempt to gather all of the earnings announcements that were specifically cited in the allegations section. We are able to obtain 78 of the 80 earnings announcements. We use Diction software to separately analyze the tone of the excerpted statements and the tone of the remainder of the earnings announcements. For the 20 earnings announcements in which the plaintiffs emphasized language within the excerpt, we separately analyze the tone of the emphasized language, as well.

The results of this analysis are presented in Table 3. The earnings announcements referenced in the complaints have a mean word count (excluding numerical terms) of 1,269 words. On average, the allegations quote $24 \%$ of the earnings announcement text. In the 20 instances where plaintiffs emphasize a portion of the excerpt, they emphasize approximately one third of the quoted language.

Univariate tests reveal that statements quoted by plaintiffs in a class action complaint are significantly more optimistic than other language in the same document (i.e., the text that was not quoted in the complaint). Specifically, quoted text has a mean (median) net optimism value of 1.35 (1.23) compared a mean (median) value of $-0.26(-0.20)$ for the non-quoted text. Moreover, the difference is pervasive - the quoted portion of the earnings announcement is more optimistic than the non-quoted portion for $85 \%$ of the earnings announcements analyzed

\footnotetext{
${ }^{20}$ Occasionally, they emphasize a portion of the excerpt through use of bolded, italicized, and/or underlined text. The first 3 examples in Appendix B feature this type of emphasis.
} 
(untabulated). As expected, when plaintiffs choose to emphasize certain statements within the excerpts, those emphasized statements tend to be even more optimistic that the quoted text, although only the median difference in Net Optimism is statistically significant. To our knowledge, this is the first concrete evidence for what many likely believed intuitively. Namely, plaintiffs target optimistic language when bringing actions against the firm.

\subsection{Comparison of Sued and Non-Sued Firms}

The prior analysis establishes that plaintiffs focus on optimistic language when bringing litigation against the firm. One plausible interpretation is that more optimistic disclosures lead to a higher probability of litigation. A more cynical view is that plaintiffs target any firm that experiences unexpectedly bad results and, with the benefit of hindsight, choose the most optimistic statements they can find and assert that they were misleading.

In order to distinguish between the two alternative perspectives on the citation of optimistic language in class action lawsuits, we incorporate a benchmark sample of similar firms that were not sued. As described earlier, each sued firm is matched to a non-sued firm in the same 2-digit SIC code and size decile, with similar stock returns to the sued firm. The stock return for each sued firm is measured between the two earnings announcements that bookend the damage period (i.e., the return window fully encompasses the lawsuit's damage period). The stock return for the sued firm's match is measured across the same number of earnings announcements, with the requirement that the sued firm and its match have return windows that start within 90 days of one another. To ensure that the sued firm and matched firm experienced comparable performance during that period, we exclude poor matches (i.e., those pairs of firms with returns differing by more than $25 \%$ over the entire window). 
We obtain electronic copies of the sued firms' earnings announcements falling within the lawsuit's damage period (regardless of whether the announcement was cited in the lawsuit) and matched firms' earnings announcements during the comparable period. To facilitate the data collection process, we use directEDGAR to retrieve the earnings announcements from the SEC's EDGAR database, as filed on form 8-K. ${ }^{21}$ This limits our sample, as the SEC did not require firms to furnish a Form 8-K with their earnings announcements prior to 2003. After excluding firms due to poor matches and losing observations because of a lack of earnings announcements and other required data, we are left with 123 sued firms and their matches. ${ }^{22}$

Table 4 Panel A provides univariate comparisons of the sued and matched firms' characteristics. Because we matched firms on size and returns, it is not surprising that those variables (Market Value of Equity and Window Return, respectively) are not significantly different across the sued and non-sued firms. The two groups are also similar in terms of historical volatility (Volatility) and book-to-market ratio (Book-to-Market). Finally, the sued firms provide more management forecasts (Log Forecasts), have greater analyst following ( $\log$ Analysts), and have larger (more negative) minimum one-day returns (Minimum Daily Return) during the damage period compared to the matched firms.

We obtained 466 earnings announcements for the 123 sued firms and 426 announcements for the matched firms, and use Diction to quantify the level of optimism (Net Optimism) in each

\footnotetext{
${ }^{21}$ Our particular search criteria was "filereasons /10/ operations and *ex*99*", which limits the 8-Ks to those reporting on the results of operations. If the firm filed multiple earnings-related 8-Ks on an earnings announcement date, we measure the characteristics of that earnings announcement as the weighted (by word count) average of the characteristics of the individual documents.

${ }^{22}$ The 123 sued firms in this analysis share similar characteristics to the 346 firms described in Table 1 in terms of damage period length and industry composition. Not surprisingly, the damage periods are heavily weighted toward the later years of our sample period due to the inability to retrieve earnings announcements from the EDGAR database in the earlier years.
} 
of the earnings announcements. ${ }^{23}$ Panel B documents that the earnings announcements of sued firms are, on average, optimistic, while those of the performance matched sample are pessimistic. The difference in tone across the two groups is statistically significant at the $1 \%$ level for both means and medians. These tests provide univariate evidence that sued firms used more optimistic language than non-sued firms in their earnings announcements (regardless of whether the sued firms' earnings announcement was actually cited in the complaint). ${ }^{24}$ The length in non-numeric words ( $\log$ Word Count) of the sued firms earnings announcements are longer in the median, though not in the mean. In contrast to the difference in tone, the two groups of firms experienced similar earnings surprises (earnings relative to analyst forecast; Earnings Surprise) and earnings growth (current quarter earnings relative to earnings four quarters prior; Earnings Growth) during their respective windows. However, sales growth (Sales Growth) for the sued firms was significantly greater than for the matched firms. Finally, insiders at the sued firms tended to sell more shares than insiders at non-sued firms (i.e., larger Net Insider Selling).

We present our multivariate analysis in Table 5. We use a conditional maximum likelihood model with a dependent variable equal to 1 for sued firms and 0 for matched firms. Specifically, we use the conditional logistic regression model (clogit in STATA), which takes into account the pair-matching to provide consistent coefficients for a sample matched on the

\footnotetext{
${ }^{23}$ Although we match on the number of earnings announcements (per IBES), the variation in sample sizes is due to an inability to obtain all of those announcements from the EDGAR database.

${ }^{24}$ We also test (but do not tabulate) whether the sued firms' damage period disclosures are more optimistic in the period of alleged misstatements than in the period when the truth was revealed (representing the end of the damage period). Following Rogers and Van Buskirk (2008), we define the truth revealing period as the last 10 days of the damage period. We compare the tone in the sued firms' documents across the two windows, expecting that the disclosures issued during the misleading period are more optimistic than the disclosures issued during the revealing period. The results confirm that the tone is significantly more optimistic during the allegedly misleading period ( $\mathrm{p}$ value $<0.01$ for both the mean and the median).
} 
dependent variable (i.e., the initiation of a class action lawsuit). ${ }^{25}$ The conditional logit calculates likelihood relative to each group (i.e., within each sued firm and its matched firm) and avoids the problem of disproportionate sampling that occurs when a sample is matched based on the dependent variable. In our case, disproportionate sampling occurs because our sample rate of litigation incidence is far higher than the rate we observe for the global population of firms.

Our particular regression models the dichotomous variable (sued/not sued) as a function of optimistic tone and other independent variables measuring firms' information environment (e.g., analyst following and book-to-market ratio) and economic performance (e.g., sales growth and earnings growth), as well as specific factors that are likely to be associated with greater litigation risk. For example, while firm size is likely to be associated with a richer information environment in general settings, we include size because only relatively large firms are likely to generate enough damages/awards to justify the costs of a lawsuit. Similarly, stock price volatility may be thought of as a general measure of uncertainty. Yet in our case, greater variation in stock price is likely to lead to greater potential damages (difference between price paid and post-damage period price) for investors. Finally, large one-day stock price drops may represent instances where a firm disclosure reveals that prior firm statements may have been materially inaccurate.

Specifically, we define the independent variables as follows:

Discretionary disclosure variables (measured at the earnings announcement level):

Net Optimism: Net optimism (optimistic words minus pessimistic words as identified by Diction) as a percentage of total non-numeric words, measured for each earnings announcement.

\footnotetext{
${ }^{25}$ For further discussion of the conditional logistic model, see Hosmer and Lemeshow (2000) or Cram et al. (2007).
} 
Optimism:

Optimistic (or optimism-increasing) words as identified by Diction as a percentage of total non-numeric words, measured for each earnings announcement.

Pessimism: $\quad$ Pessimistic (or optimism-decreasing) words as identified by Diction as a percentage of total non-numeric words, measured for each earnings announcement.

Log Forecasts: $\quad$ The log of one plus the number of management forecasts issued during the period between the current and prior earnings announcement.

Mandatory disclosure variables (measured at the earnings announcement level):

Earnings Surprise: $\quad$ Reported earnings minus mean $\mathrm{I} / \mathrm{B} / \mathrm{E} / \mathrm{S}$ estimate, scaled by stock price, with both the estimate and the stock price measured three trading days prior to the earnings announcement.

Earnings Growth: The change in quarterly income before extraordinary items relative to the same quarter of the previous year, scaled by total assets.

Sales Growth: $\quad$ The percentage growth in quarterly sales revenue relative to the same quarter of the previous year.

Other control variables (measured at the earnings announcement level):

Log Word Count: $\quad$ The natural logarithm of the earnings announcement word count for each earnings announcement during the damage window.

Net Insider Selling: $\quad$ The sign-preserving square root of net insider selling (in dollars). Specifically, we take the total dollar value of officers' and directors' open market sales less open market purchases during the period between the current and prior earnings announcement. We then take the square root of the absolute value of this net trading volume. For net purchases, we multiple this value by negative one, so that positive values represent net selling and negative values represent net purchasing.

Firm-level control variables:

Volatility: $\quad$ Stock price volatility, measured over the 90 days prior to the beginning of the damage period 
Book-to-Market:

Log Analysts:

Market Value of Equity:

Window Return:
The ratio of book value to market value, measured prior to the beginning of the damage period

The natural logarithm of one plus the number of analysts following the firm, measured prior to the beginning of the damage period

The natural logarithm of market value of equity, calculated prior to the beginning of the damage period

Stock return during the window used to identify the matched firms (i.e., from the earnings announcement immediately prior to the beginning of the damage period to the earnings announcement ending or immediately following the end of the damage period)

Minimum Daily Return: The smallest (i.e., most negative) one day return during the damage period.

The results of our regressions are shown in Table 5. We find that the percent of netoptimistic language is a significant predictor of class action litigation. Specifically, Net Optimism has a significantly positive coefficient equal to 0.474 (p-value $<0.01)$. A one standard deviation increase in Net Optimism increases in the odds of being sued by a factor of 1.61. To illustrate the economic magnitude, $9.2 \%$ of S\&P 500 firms at the start of 2008 were subject to securities litigation filed in 2008 (Securities Class Action Filings 2008: A Year In Review 2009). Using that $9.2 \%$ figure as a baseline, a one standard deviation increase in optimism would increase the probability of being sued to approximately $14 \%$. These results are in accord with the univariate results presented earlier.

We also find that firms issuing more discretionary disclosure in the form of management forecasts have a greater propensity to be sued - the coefficient on Log Forecasts is positive and significant (p-value $<0.01$ ). This result is consistent with the results in Rogers and Van Buskirk 
(2008). Specifically, they show that managers reduce their forecast issuance after being sued, presumably after gaining a better understanding of the particular disclosure behavior that puts them at risk.

Many of the remaining earnings announcement level independent variables demonstrate strong relations with litigation. While earnings surprise (Earnings Surprise) and earnings growth (Earnings Growth) are not significantly associated with the probability of being sued, we do find significant associations for the other variables. In particular, insider trading (Net Insider Selling), sales growth (Sales Growth), the length of the earnings announcements (Log Word Count), and the largest one-day price decline (Minimum Daily Return) are all significantly associated with the likelihood of being sued.

We find that firms with poorer stock performance over the damage period (Window Return), larger firms (Market Value of Equity), and firms with greater analyst following (Log Analysts) have a higher likelihood of being sued. In contrast, volatility of stock returns (Volatility) and book-to-market ratio (Book-to-Market) are not significantly associated with the probability of litigation.

\section{Additional analysis}

In the previous section, we established a relation between optimistic tone and litigation risk. In this section, we evaluate two alternative explanations for why such a relation would exist.

One story is essentially proposed by plaintiffs: Managers released very optimistic disclosures, leading to inflated stock prices that subsequently dropped when the true conditions of the firm were revealed. An alternative explanation (proposed by critics of the current 
litigation environment) is that plaintiff attorneys identify firms experiencing large stock price drops, with the hope of identifying earlier statements that (with the benefit of hindsight) were inaccurate. The types of statements most likely to be identified as ex post inaccurate are optimistic statements.

Our earlier results cannot distinguish between the two alternatives. However, the two alternatives yield different inferences for different dimensions of disclosure optimism. In the "plaintiff's" scenario, we expect that stock prices respond to both optimistic and pessimistic language, so that litigation is more likely when more optimistic terms are used and are not tempered by pessimistic terms. In contrast, in the "critic's" scenario, when lawyers are simply searching for optimistic language to cite in their complaint, the existence of offsetting pessimistic language would have no effect on the likelihood of being sued. Similarly, the existence of more optimistic words in total (rather than the percentage of optimistic words in the document, which we used in earlier sections) would put the firm at greater risk if more words simply provided more opportunity for plaintiff attorneys to allege misleading statements.

The results of our analysis are shown in Table 6. In the first column, we perform the logistic regression shown in Table 5, substituting Optimism and Pessimism for Net Optimism. When Net Optimism is bifurcated into its Optimism and Pessimism subcomponents, both are associated with the likelihood of litigation ( $\mathrm{p}$-values $<0.05$ ) in approximately the same magnitude as the net number. This result indicates that a one unit increase in optimistic language has approximately the same effect as a one unit decrease in pessimistic language in terms of a greater chance of being sued. Viewed from a different perspective, the use of cautionary language to offset more positive statements seems to be associated with reduced litigation risk. 
In the second column, we include both scaled and unscaled Net Optimism in the regression, and find that the scaled version remains significantly positive ( $\mathrm{p}$-value $<0.01$ ) while the unscaled version is not significant at conventional levels. An F-test confirms that the coefficient on the scaled version is significantly greater than that of the unscaled version (pvalue $<0.01)$. The results from both regressions presented in Table 6 cast doubt on the "critic's" view that plaintiff attorneys are simply cherry-picking optimistic language from disclosures without regard to the context in which those disclosures were made. Repeating the caveat presented earlier, these results do not provide conclusive evidence that shareholder litigation has merit, but they do indicate that sued firms' disclosures are systematically different from non-sued disclosures in the manner suggested by plaintiffs.

\section{Conclusion}

We study the tone of earnings announcements issued by firms sued in disclosure-related litigation with the goal of identifying whether optimistic disclosures are associated with shareholder litigation. Using text-analysis software to quantify optimism, we contribute several findings to the existing literature. First, while class action complaints cite a broad variety of communications, earnings announcements appear to be the most consistently cited source of alleged misstatements. Second, the tone of the statements quoted in the class action complaint is significantly more optimistic than the tone of the non-quoted portion of the cited document, suggesting that optimistic language is a target for plaintiff attorneys. Third, the tone of earnings announcements issued by sued firms during the damage period is more optimistic than the tone 
of earnings announcements issued during a comparable period by non-sued firms from the same industry and with similar economic performance.

The implications of our results should be of interest to both managers and regulators. Because firms are unlikely to end the practice of issuing earnings announcements, managers will not be able to reduce litigation risk by eliminating this category of disclosure even though it tends to put the firm at risk - earnings announcements will continue to be scrutinized by potential plaintiffs. However, our evidence suggests that managers may be able to reduce litigation risk by dampening the tone of their earnings announcements. We also show that forecast issuance is positively associated with lawsuit incidence, which may encourage firms to curtail the practice. Results in Rogers and Van Buskirk (2008) suggest that managers who experience litigation learn this and reduce their forecasting behavior following litigation.

From a regulatory perspective, these results contribute to the long-standing debate over the merits of shareholder litigation. While our study does not conclusively show that managers of sued firms intentionally or recklessly mislead investors with overly optimistic statements, it does indicate that sued firms' disclosures are consistently more optimistic than non-sued firms in similar circumstances, consistent with the typical plaintiff allegation. 


\section{Appendix A}

Example words used in calculating Diction's optimism score

Measured optimism is equal to [praise + satisfaction + inspiration $-($ blame + hardship + denial)]/[non-numeric words analyzed] x 100

\section{Optimistic words:}

Praise: $\quad$ greater, bright, nice, favorable, superior, excellent, best, impressive, successful, positive, stronger

Satisfaction: satisfied, thrilled, fortunately, refreshingly, gladly, encourage, determined, excite, prosper, confident

Inspiration: pride, loyalty, support, commitment, quality, excellence, trust, improvement, progress, discipline, promise

\section{Pessimistic words:}

Blame: threatening, bleak, unnecessary, vulnerable, disappointing, weaker, disastrous, grimmer, mediocre, inferior

Hardship: threat, failing, pained, overwhelm, troubles, discourages, setbacks, suffer, alarms, distressed, risking

Denial: nobody, hadn't, hasn't, didn't, can't, shouldn't, nowhere, haven't, nothing, nixed 


\section{Appendix B}

4 Examples of specific language quoted in shareholder lawsuits

Example 1: In re Keithley Instruments, Inc. Securities Litigation, Consolidated Amended Class Action Complaint, 8/29/2001

"Orders, sales and earnings all continued to grow to record levels. We continue to gain market share because of our wealth of applications knowledge and technology leadership, and believe our key industries offer very good long-term potential for Keithley. We also continue to be pleased with customer acceptance of our new semiconductor characterization system introduced last summer. New products will remain a critical element in our success."

"Quarter to quarter results will always be order dependent, but our record backlog along with current business activities lead us to believe that sales pretax earnings of the second quarter will exceed those of the first quarter.

The company is estimating sales growth for fiscal 2001 in excess of 25 percent over fiscal year 2000 sales of $\$ 151$ million based on continued growth in the optoelectronics, semiconductor and telecommunications industries."

[citing a January 18, 2001 earnings announcement. Emphasis added by plaintiffs.] 
Appendix B (continued)

4 Examples of specific language quoted in shareholder lawsuits

Example 2: $\quad$ In Re VoiceFlash Networks, Inc. Securities Litigation, Second Amended Class Action Complaint, 5/31/2005

the Company reported net income of $\$ 459,713$, or $\$ 0.04$ on a per share basis, compared to a net loss of \$426,000, or (\$0.07) per share, for the same period in 2001. The increase in the Company's per share results for the quarter ended January 31, 2002 from the comparable 2001 period is due primarily to the October 2001 acquisition of United Capturdyne Technologies, Inc. For the quarter ended January 31, 2002, the Company reported sales revenue of $\$ 1,189,000$, compared to sales revenue of $\$ 61,100$ for the same period in 2001.

Commenting on the report, VoiceFlash Networks CEO Robert J. Kaufman said, "We are very pleased with the company's second-quarter results, and we confidently expect this revenue and earnings momentum to continue in this fiscal year. Going forward, VoiceFlash's reach is extending and accelerating in many areas. The strategic addition of United Capturdyne in October provides us with state-of-the-art technology and broader capabilities as we transition into an even wider-ranging financial services, Company."

Kaufman continued, "We have just completed the most successful quarter in the company's history. We continue to develop compelling new products and services, and we fully anticipate further growth and expansion in 2002 and beyond, as we draw on additional strategic relationships and add new dimensions to the company's capacities and capabilities."

[citing a March 15, 2002 earnings announcement. Emphasis added by plaintiffs.] 
Appendix B (continued)

4 Examples of specific language quoted in shareholder lawsuits

Example 3: In Re Pozen Inc. Securities Litigation, Amended Class Action Complaint, $4 / 25 / 2008$

JOHN PLACHETKA, CHAIRMAN, PRESIDENT \& CEO, POZEN INC.... .

First, I would like to update you on Trexima. As you recall in December, the FDA required additional information about the large data set from GSK that was included in our November response. This included patient demographics and study designs, in conclusion criteria, exclusion criteria, adverse event collection procedures, as well as comparative sumatriptan data from other studies GSK had conducted since sumatriptan research was begun in the late 1980s.

Now while we had hoped to file the response by the end of December, the amount of data included in the amended response required more time than I initially thought on the part of both POZEN and GSK to compile, analyze and put it into the format requested by the FDA.

We announced in early February that the amended response had been filed with the FDA and now we are awaiting the FDA's acceptance of our submission. We expect that the FDA will take up to six months to review the amended response, which would put the action date sometime in early August.

GSK has also stated in their last earnings press release that if Trexima is approved, they are targeting a second half 2007 launch.

We are confident that we have put together the response as requested by FDA and we continue to believe that the data indicates that Trexima offers superior efficacy without a significantly increased risk of adverse events, including cardiac adverse events compared to its components. But we fully understand and remind all of you that the final approval decision is made by FDA.

Assuming that Trexima is approved in mid-2007, we expect to receive the $\$ 20$ million in milestone payment from GSK along with royalties for whatever portion of the year Trexima is marketed.

BILL HODGES, CFO \& SVP, FINANCE AND ADMINISTRATION, POZEN, INC.: ... For the full 2007 year, we expect total revenue to be in the range of $\$ 50$ million to $\$ 55$ million, which includes revenue of . . \$20 million in milestone payments from Trexima assuming that Trexima gets approved, which is $\$ 10$ million upon approval and \$10 million upon notice from GSK of their intent to commercialize.

[citing a March 7, 2007 earnings-related conference call. Emphasis added by plaintiffs.] 


\title{
Appendix B (continued)
}

4 Examples of specific language quoted in shareholder lawsuits

Example 4: In Re EVCI Career Colleges Holding Corp. Securities Litigation, Consolidated Amended Class Action Complaint, 7/21/2006

EVCI Career Colleges Incorporated (Nasdaq : EVCI) announced an enrollment increase of more than $30 \%$ for the fall 2003 semester at Interboro Institute's four college sites. The enrollment in the fall 2003 semester was approximately 2300 students as compared to 1,750 students in the fall 2002 semester.

Dr. John J. McGrath, Chief Executive Officer and President expressed great satisfaction with the increases in new student enrollments and in the success of the college's new retention strategies.

Percentage of enrollment increase, when comparing year over year semester enrollment, is a key valuation driver in the for-profit education sector . According to [a sector research analyst], EVCI's peer group within the post secondary education industry has averaged between $15 \%$ and $20 \%$ growth in year-over-year semester enrollments . "Measured by this standard, it is our opinion that EVCI's stock is undervalued," stated Dr. Arol I. Buntzman, Chairman of EVCI.

\begin{abstract}
$* * *$
According to Dr. McGrath, "It is noteworthy that EVCI's 30\% plus growth rate results solely from internally generated enrollments at existing campuses rather than growth by adding new Interboro sites or acquisitions." Interboro demonstrated significant enrollment increases at each college site.
\end{abstract}

[citing a 10/22/2003 press release] 


\section{References}

Alexander, J. C. 1991. Do the Merits Matter? A Study of Settlements in Securities Class Actions. Stanford Law Review 43 (3):497-598.

Baginski, S. P., J. M. Hassell, and W. A. Hillison. 2000. Voluntary Causal Disclosures: Tendencies and Capital Market Reaction. Review of Quantitative Finance and Accounting 15 (4):371-389.

Baginski, S. P., J. M. Hassell, and M. D. Kimbrough. 2002. The Effect of Legal Environment on Voluntary Disclosure: Evidence from Management Earnings Forecasts Issued in U.S. and Canadian Markets. The Accounting Review 77 (1):25-50.

Baker, T., and S. J. Griffith. 2008. How the Merits Matter: D\&O Insurance and Securities Settlements. SSRN eLibrary.

Bettman, J. R., and B. A. Weitz. 1983. Attributions in the Board Room: Causal Reasoning in Corporate Annual Reports. Administrative Science Quarterly 28 (2):165-183.

Bligh, M. C., J. C. Kohles, and J. R. Meind1. 2004. Charting the Language of Leadership: A Methodological Investigation of President Bush and the Crisis of 9/11. Journal of Applied Psychology 89 (3):562-574.

Cho, J., M. P. Boyle, H. Keum, M. D. Shevy, D. M. McLeod, D. V. Shah, and Z. Pan. 2003. Media, Terrorism, and Emotionality: Emotional Differences in Media Context and Public Reactions to the September 11th Terrorist Attacks. Journal of Broadcasting \& Electronic Media 47 (3):309-327.

Coffee, J. C., Jr. 2006. Reforming the Securities Class Action: An Essay on Deterrence and its Implementation. Columbia Law Review 106 (7):1534-1586.

Cram, D. P., V. Karan, and I. Stuart. 2007. Three Threats to Validity of Choice-Based and Matched Sample Studies in Accounting Research. SSRN eLibrary.

Davis, A. K., J. Piger, and L. M. Sedor. 2008. Beyond the Numbers: Managers' Use of Optimistic and Pessimistic Tone in Earnings Press Releases. SSRN eLibrary.

Demers, E. A., and C. Vega. 2008. Soft Information in Earnings Announcements: News or Noise? SSRN eLibrary.

Field, L., M. Lowry, and S. Shu. 2005. Does Disclosure Deter or Trigger Litigation? Journal of Accounting and Economics 39 (3):487-507.

Francis, J., D. Philbrick, and K. Schipper. 1994. Shareholder Litigation and Corporate Disclosures. Journal of Accounting Research 32 (2):137-164.

Henry, E. 2008. Are Investors Influenced by How Earnings Press Releases Are Written? Journal of Business Communication 45 (4):363-407. 
Hosmer, D. W., and S. Lemeshow. 2000. Applied Logistic Regression: Wiley-Interscience.

Interim Report of the Committee on Capital Markets Regulation. 2006. Committee on Capital Markets Regulation.

Johnson, M. F., R. Kasznik, and K. K. Nelson. 2001. The Impact of Securities Litigation Reform on the Disclosure of Forward-Looking Information by High Technology Firms. Journal of Accounting Research 39 (2):297-327.

Johnson, M. F., K. K. Nelson, and A. C. Pritchard. 2007. Do the Merits Matter More? The Impact of the Private Securities Litigation Reform Act. Journal of Law, Economics, \& Organization 23 (3):627-652.

Kothari, S. P., X. Li, and J. E. Short. 2008a. The Effect of Disclosures by Management, Analysts, and Financial Press on Cost of Capital, Return Volatility, and Analyst Forecasts: A Study Using Content Analysis. SSRN eLibrary.

Kothari, S. P., S. Shu, and P. D. Wysocki. 2008b. Do Managers Withhold Bad News? Journal of Accounting Research Forthcoming.

Lang, M. H., and R. J. Lundholm. 2000. Voluntary Disclosure and Equity Offerings: Reducing Information Asymmetry or Hyping the Stock? Contemporary Accounting Research 17 (4):623-662.

Li, F. 2008. Annual Report Readability, Current Earnings, and Earnings Persistence. Journal of Accounting and Economics 45 (2-3):221-247.

Lougee, B. A., and C. A. Marquardt. 2004. Earnings Informativeness and Strategic Disclosure: An Empirical Examination of "Pro Forma" Earnings. The Accounting Review 79 (3):769795.

Mayew, W. J., and M. Venkatachalam. 2008. The Power of Voice: Managerial Affective States and Future Firm Performance. SSRN eLibrary.

McVay, S. E. 2006. Earnings Management Using Classification Shifting: An Examination of Core Earnings and Special Items. Accounting Review 81 (3):501-531.

Miller, G. S. 2002. Earnings Performance and Discretionary Disclosure. Journal of Accounting Research 40 (1):173-204.

Rogers, J. L., and P. C. Stocken. 2005. Credibility of Management Forecasts. The Accounting Review 80 (4):1233-1260.

Rogers, J. L., and A. Van Buskirk. 2008. Shareholder Litigation and Changes in Disclosure Behavior. Journal of Accounting and Economics In Press, Corrected Proof.

Schrand, C. M., and B. R. Walther. 2000. Strategic Benchmarks in Earnings Announcements: The Selective Disclosure of Prior-Period Earnings Components. The Accounting Review 75 (2):151-177. 
Securities Class Action Filings 2008: A Year In Review. 2009. Cornerstone Research.

Skinner, D. J. 1994. Why Firms Voluntarily Disclose Bad News. Journal of Accounting Research 32 (1):38-60.

- 1997. Earnings Disclosures and Stockholder Lawsuits. Journal of Accounting and Economics 23 (3):249-282.

Tetlock, P. C., M. Saar-Tsechansky, and S. Macskassy. 2008. More Than Words: Quantifying Language to Measure Firms' Fundamentals. Journal of Finance 63 (3):1437-1467.

Yuthas, K., R. Rogers, and J. F. Dillard. 2002. Communicative Action and Corporate Annual Reports. Journal of Business Ethics 41 (1):141-157. 


\section{Table 1: Distribution of lawsuits}

This table shows the distribution of 346 disclosure-related securities lawsuits with damage periods beginning after Regulation FD. Inclusion in this sample requires data in CRSP, Compustat, $\mathrm{I} / \mathrm{B} / \mathrm{E} / \mathrm{S}$, and First Call, as well as damage periods that include at least one earnings announcement and the existence of both a pre- and post-damage period earnings announcement. Panel A provides the distribution of the year in which the lawsuits were filed. Panel B provides the distribution of the length of time (in months) that the damage periods extended. Panel $\mathrm{C}$ provides a list of all industries, by 2 -digit SIC code, in which $5 \%$ or more of the lawsuits fell.

\section{Panel A: Distribution of lawsuit dates}

\begin{tabular}{c|cc}
\hline Year of suit filing & \multicolumn{2}{|c}{ Lawsuits } \\
\hline 2001 & 18 & $5 \%$ \\
2002 & 33 & $10 \%$ \\
2003 & 45 & $13 \%$ \\
2004 & 72 & $21 \%$ \\
2005 & 58 & $17 \%$ \\
2006 & 34 & $10 \%$ \\
2007 & 64 & $18 \%$ \\
2008 & 22 & $6 \%$ \\
Total & 346 & $100 \%$ \\
\hline
\end{tabular}

Panel B: Distribution of the length of the damage period (in 6-month increments)

\begin{tabular}{c|cc}
\hline Number of months & \multicolumn{2}{|c}{ Lawsuits } \\
\hline 0 & 1 & $0 \%$ \\
$1-6$ & 118 & $34 \%$ \\
$7-12$ & 102 & $30 \%$ \\
$13-18$ & 52 & $15 \%$ \\
$19-24$ & 31 & $9 \%$ \\
$25-30$ & 14 & $4 \%$ \\
$31-36$ & 3 & $1 \%$ \\
$37-42$ & 8 & $2 \%$ \\
$43-48$ & 5 & $1 \%$ \\
$49-54$ & 3 & $1 \%$ \\
$55-60$ & 9 & $3 \%$ \\
Total & 346 & $100 \%$ \\
\hline
\end{tabular}

(Table 1 continues on following page) 


\section{Table 1 (continued)}

Panel C: Distribution of lawsuits by industry (2-digit SIC codes with 5\% or more of the suits)

\begin{tabular}{l|cc}
\hline 2-digit SIC Code & \multicolumn{2}{|c}{ Lawsuits } \\
\hline 28: Chemicals and Allied Products & 60 & $17 \%$ \\
73: Business Services & 44 & $13 \%$ \\
36: Electronic and Other Electronic Equipment & 29 & $8 \%$ \\
38: Measure, Analyze, Control Instruments & 23 & $7 \%$ \\
63: Insurance Carriers & 21 & $6 \%$ \\
\cline { 2 - 3 } Total in highly-represented industries & 177 & $51 \%$ \\
\hline
\end{tabular}




\section{Table 2: Lawsuit subsample - analysis of class action complaints}

This table shows the distribution of a subsample of 20 lawsuits selected at random from all disclosure-related lawsuits with damage periods beginning after Regulation FD and with available data on CRSP, Compustat, $\mathrm{I} / \mathrm{B} / \mathrm{E} / \mathrm{S}$, and First Call. Panel A provides the distribution of the lawsuit dates. Panel B provides the distribution of the length of time (in months) that the damage periods extended. Panel $\mathrm{C}$ summarizes the documents cited in the allegations section of the lawsuit. The left column of Panel $\mathrm{C}$ indicates the percentage of the subsample that cited each document at least once. The right columns of Panel $\mathrm{C}$ tabulate the frequency with which each document category was cited.

\section{Panel A: Distribution of lawsuit dates}

\begin{tabular}{c|cc}
\hline Year of suit filing & \multicolumn{2}{|c}{ Lawsuits } \\
\hline 2001 & 2 & $10 \%$ \\
2002 & 1 & $5 \%$ \\
2003 & 1 & $5 \%$ \\
2004 & 3 & $15 \%$ \\
2005 & 4 & $20 \%$ \\
2006 & 3 & $15 \%$ \\
2007 & 3 & $15 \%$ \\
2008 & 3 & $15 \%$ \\
\cline { 2 - 3 } Total & 20 & $100 \%$ \\
\hline
\end{tabular}

Panel B: Distribution of the length of the damage period (in 6-month increments)

\begin{tabular}{c|cc}
\hline Number of months & \multicolumn{2}{|c}{ Sample Population } \\
\hline 0 & 1 & $5 \%$ \\
$1-6$ & 4 & $20 \%$ \\
$7-12$ & 8 & $40 \%$ \\
$13-18$ & 3 & $15 \%$ \\
$19-24$ & 1 & $5 \%$ \\
$25-30$ & 1 & $5 \%$ \\
$31-36$ & 0 & $0 \%$ \\
$37-42$ & 0 & $0 \%$ \\
$43-48$ & 0 & $0 \%$ \\
$49-54$ & 1 & $5 \%$ \\
$55-60$ & 1 & $5 \%$ \\
Total & 20 & $100 \%$ \\
\hline
\end{tabular}

(Table 2 continues on following page) 
Table 2 (continued)

Panel C: Distribution of the source documents cited in the allegation section of the lawsuit

\begin{tabular}{|c|c|c|c|}
\hline & $\begin{array}{l}\text { \% of lawsuits citing } \\
\text { document category }\end{array}$ & \multicolumn{2}{|c|}{ Total Documents Cited } \\
\hline \multicolumn{4}{|l|}{ Earnings related: } \\
\hline Earnings Announcement & $90 \%$ & 80 & \\
\hline \multirow{2}{*}{$\begin{array}{l}\text { Related conference call } \\
\text { Total EA }\end{array}$} & \multirow[t]{2}{*}{$60 \%$} & 28 & \\
\hline & & 108 & $37 \%$ \\
\hline \multicolumn{4}{|l|}{ SEC Filings: } \\
\hline $10-Q$ & $70 \%$ & 51 & \\
\hline $10-\mathrm{K}$ & $55 \%$ & 20 & \\
\hline Other & \multirow[t]{2}{*}{$20 \%$} & 4 & \\
\hline Total SEC & & 75 & $26 \%$ \\
\hline \multicolumn{4}{|l|}{ Other cited items: } \\
\hline Press Release & $75 \%$ & 91 & $31 \%$ \\
\hline Conference call & $10 \%$ & 3 & $1 \%$ \\
\hline Investor conference & $10 \%$ & 2 & $<1 \%$ \\
\hline Interview & $35 \%$ & 14 & $5 \%$ \\
\hline Other & $5 \%$ & 1 & $<1 \%$ \\
\hline Total Documents & & 294 & $100 \%$ \\
\hline
\end{tabular}




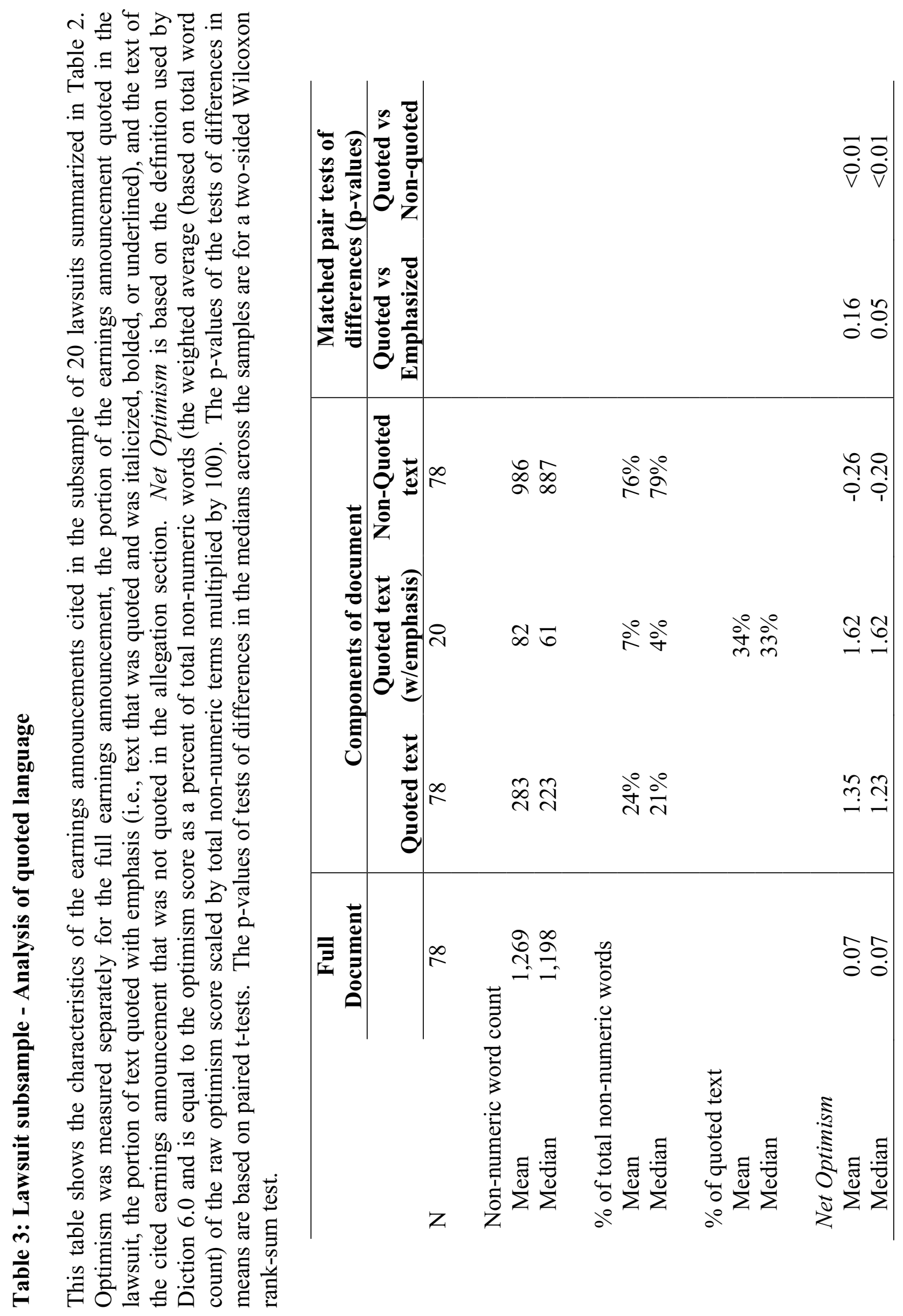




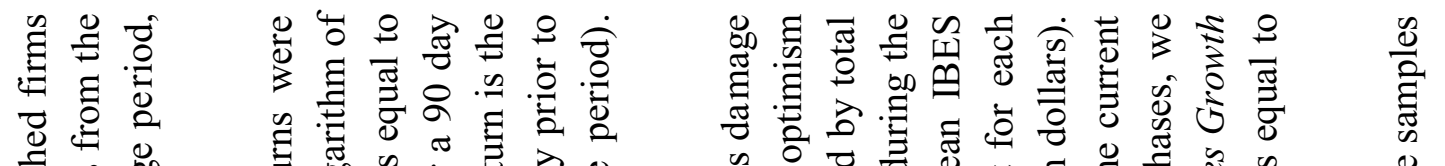

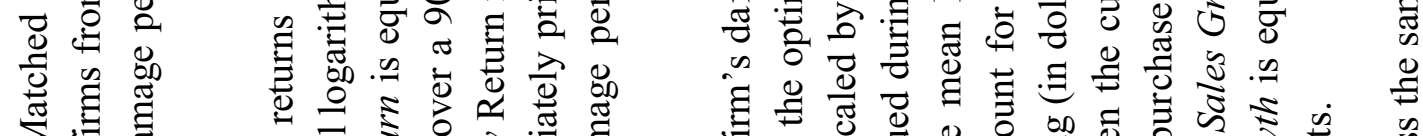

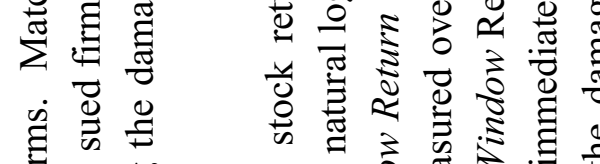

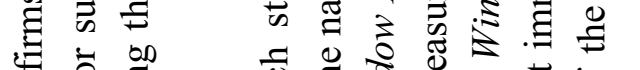

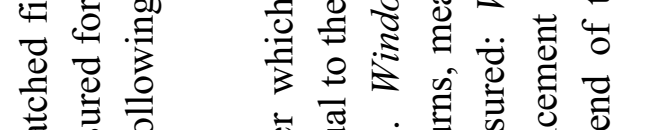

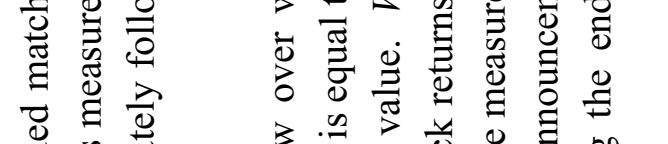

की

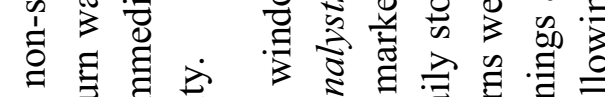

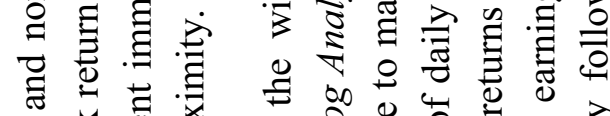

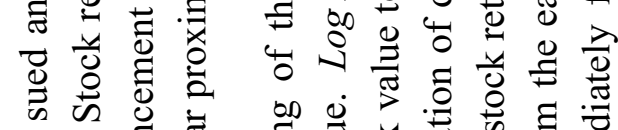

ஸे

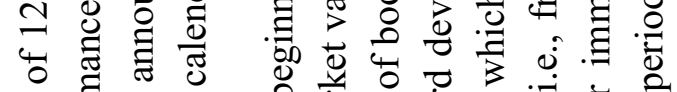

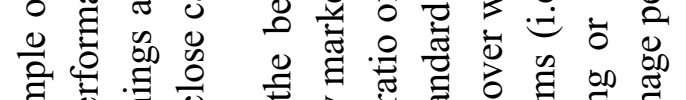

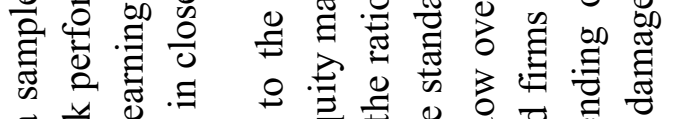

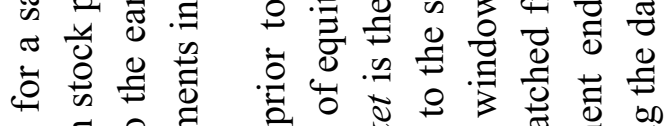

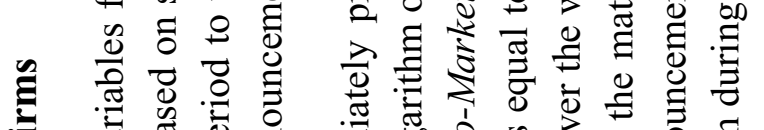

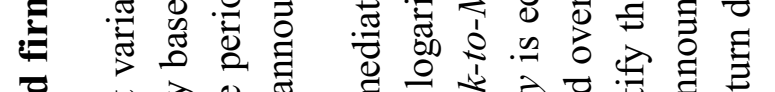

ठ 요

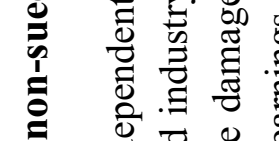

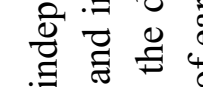

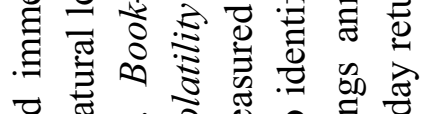

ठ

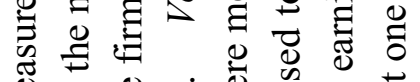

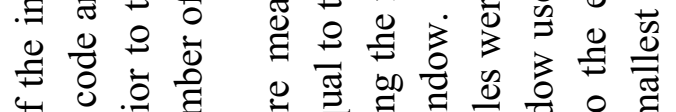

离

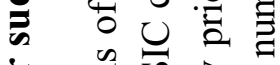

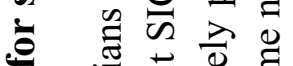

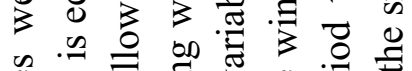

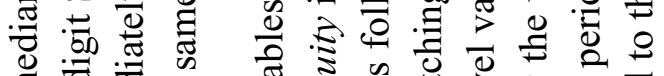

.

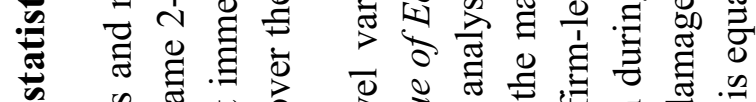

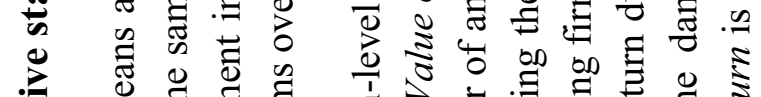

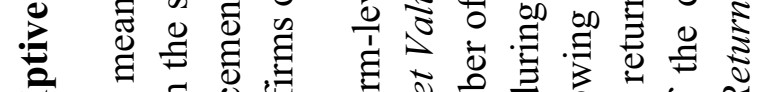

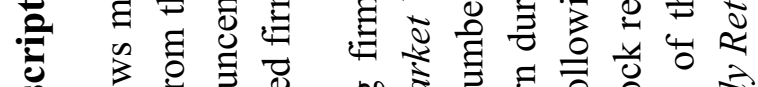

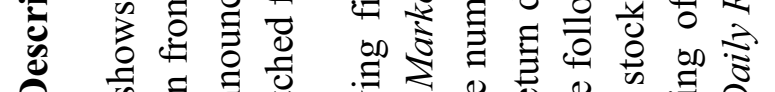

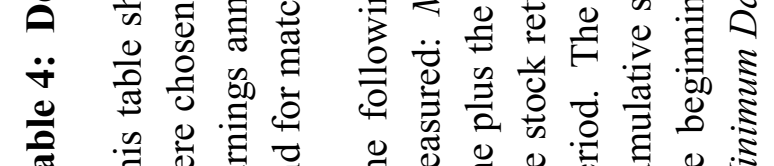

向

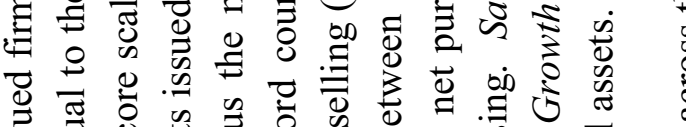

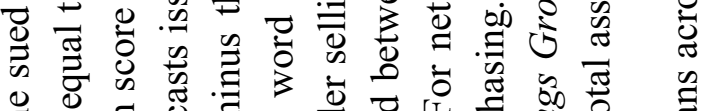

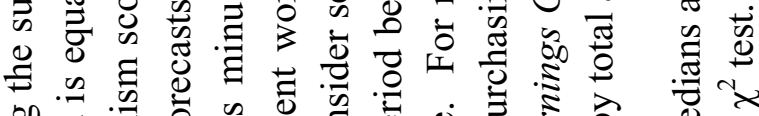

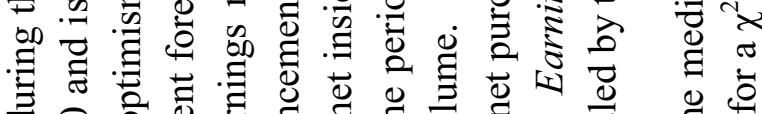

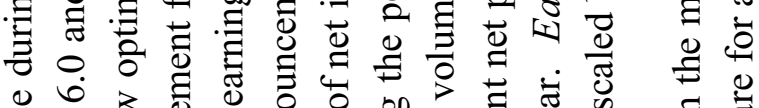

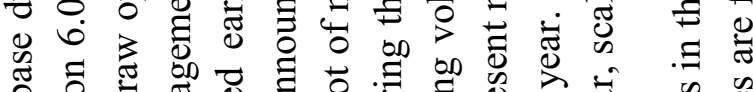

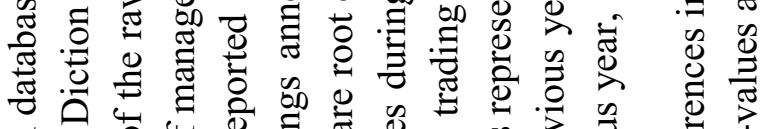

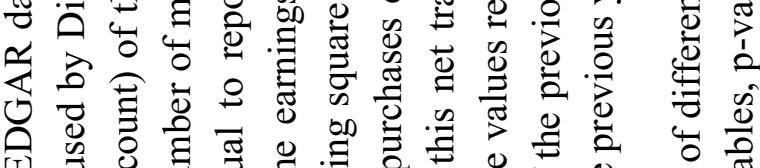

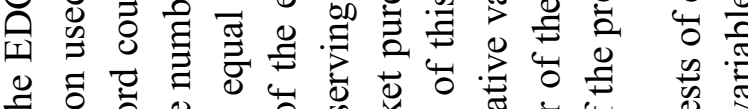

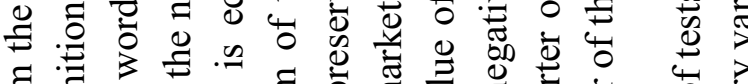

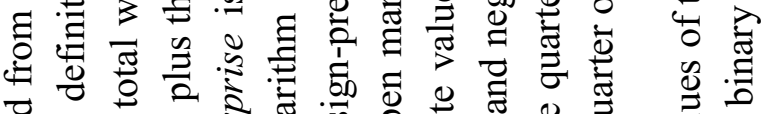

च

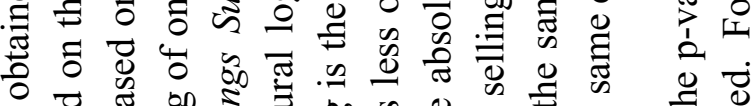

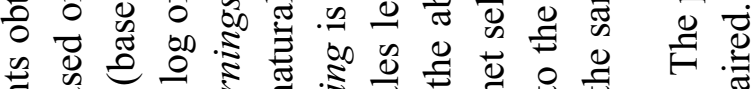

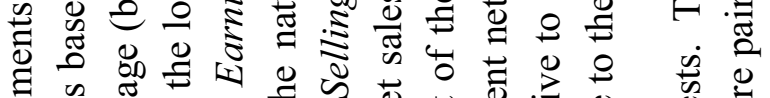

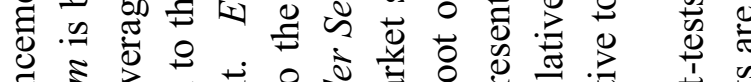

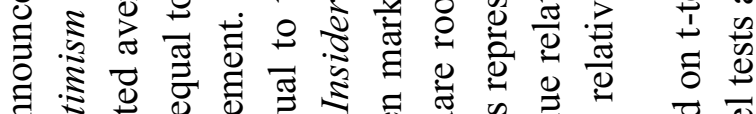

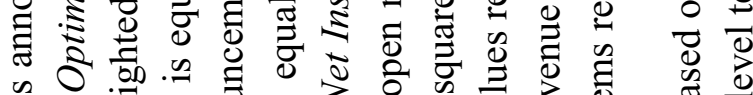

की

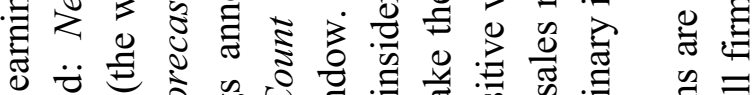

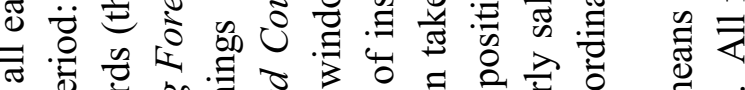

苛

ग

节离官.

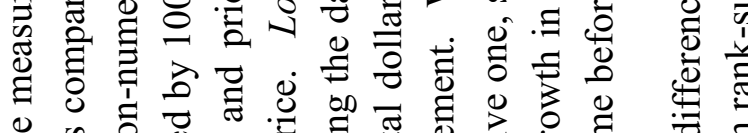

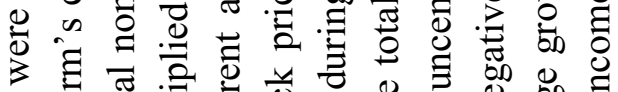

纯

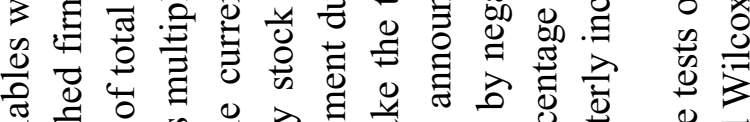

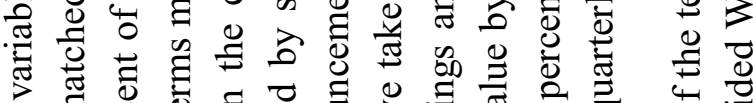

on

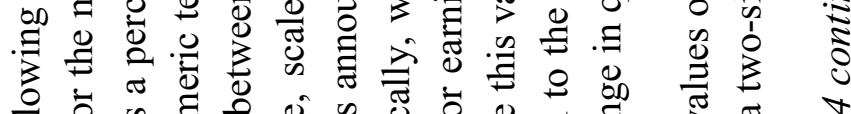

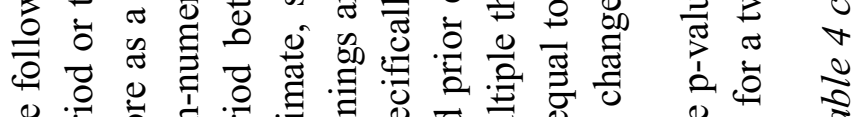

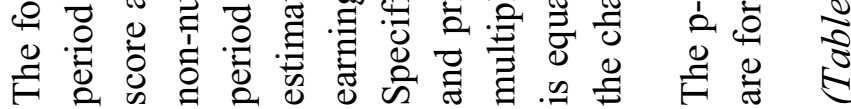



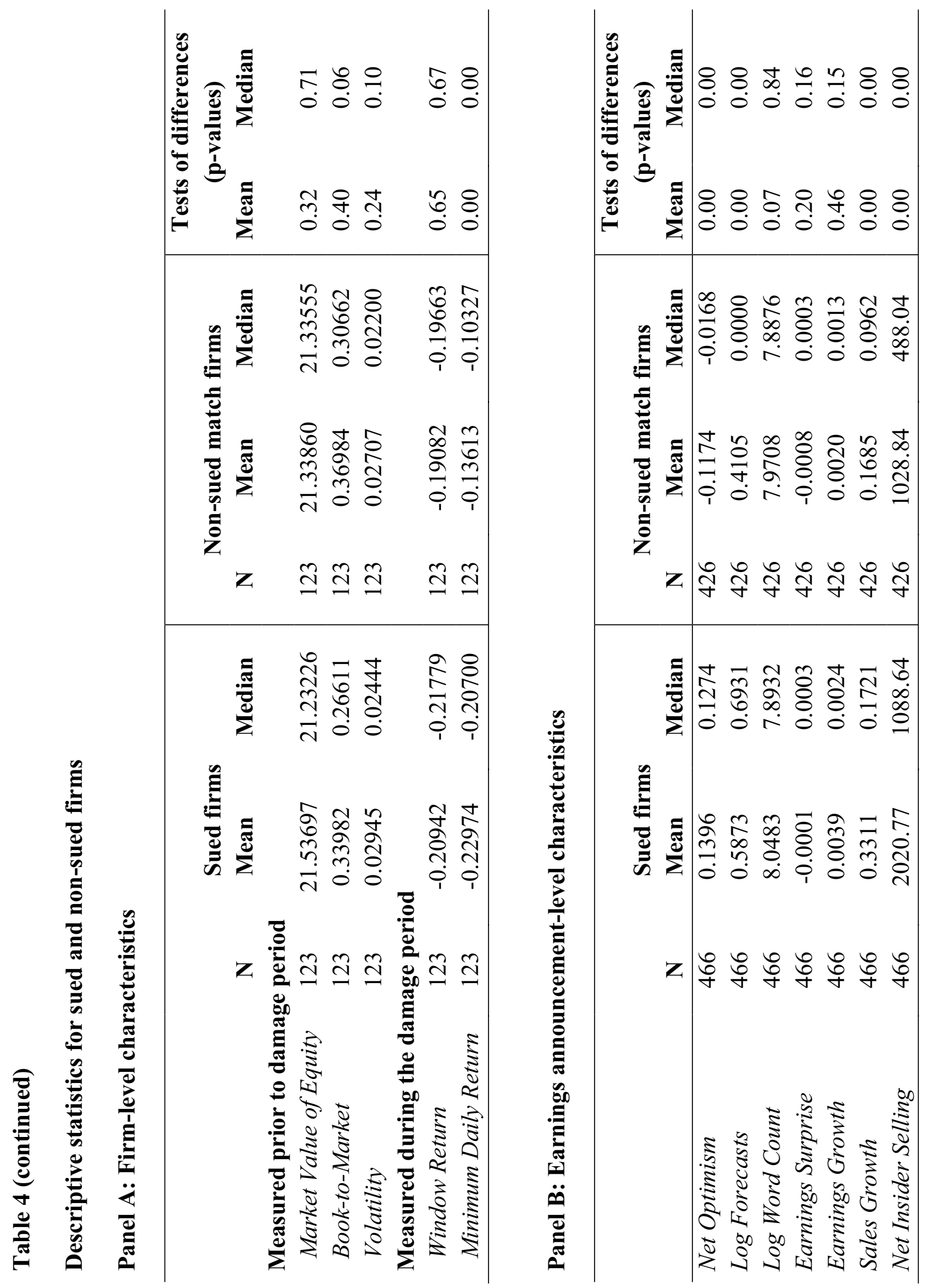


\section{Table 5: Litigation conditional logit}

This conditional logit of the propensity for being sued is measured over a pool of 466 observations from 123 sued firms and 426 observations from 123 matched firms, each observation representing an individual earnings announcement. The variables are as defined in Table 4. Significance levels are indicated by $* * *, * *$, and $*$ representing $1 \%, 5 \%$, and $10 \%$ levels, respectively (2-tailed).

\begin{tabular}{|l|cc|}
\hline & Coefficient & z-stat \\
\hline Net Optimism & $0.4656^{* * *}$ & 3.13 \\
Log Forecasts & $0.7229^{* * *}$ & 3.33 \\
Earnings Surprise & -7.1976 & -0.42 \\
Earnings Growth & -3.9850 & -1.18 \\
Sales Growth & $0.9491^{* * *}$ & 3.37 \\
Log Word Count & $0.7232^{* * *}$ & 2.95 \\
Net Insider Selling & $0.0002^{* * *}$ & 3.63 \\
Volatility & 19.3690 & 1.23 \\
Book-to-Market & 1.0014 & 1.63 \\
Log Analysts & $0.8456^{* * *}$ & 2.72 \\
Market Value of Equity & $0.9163^{* * *}$ & 3.91 \\
Window Return & $-53.1767^{* * *}$ & -5.67 \\
Minimum Daily Return & $-20.2168^{* * *}$ & -10.36 \\
& & \\
Pseudo R & & \\
No. Observations & $49.2 \%$ & \\
\hline
\end{tabular}




\section{Table 6: Robustness tests of alternative optimism specifications}

This conditional logit of the propensity for being sued is measured over a pool of 466 observations from 123 sued firms and 426 observations from 123 matched firms, each observation representing an individual earnings announcement. The variables are as defined in Table 4 with the following exception. First, Net Optimism (Unscaled) is equal to Net Optimism (Scaled), as used in previous tables, except that is it not scaled by the total non-numeric words in the earnings announcement. Second, the subcomponents of Net Optimism (Scaled) - Optimism and Pessimism - are based on the definitions used by Diction 6.0 and are equal to the relative score as a percent of total non-numeric words (the weighted average (based on total words count) of the raw score scaled by total non-numeric terms multiplied by 100). Significance levels are indicated by $* * *, * *$, and $*$ representing $1 \%, 5 \%$, and $10 \%$ levels, respectively (2-tailed).

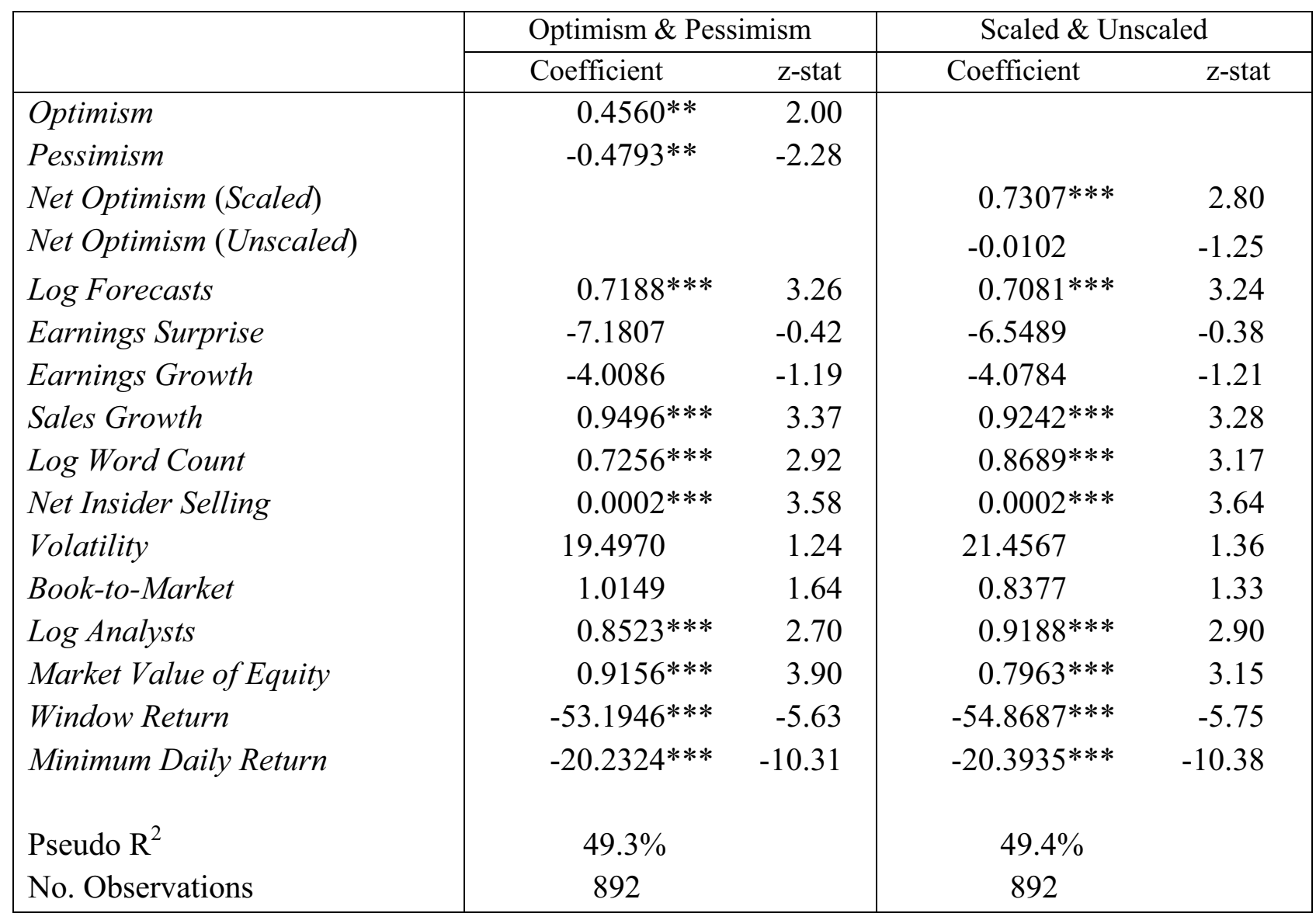

